\title{
EDUCAÇÃO A DISTÂNCIA: O SIGNIFICADO DA DOCÊNCIA E AS ESTRATÉGIAS DE FORTALECIMENTO PARA SUA ATUAÇÃO
}

\section{DISTANCE EDUCATION: THE MEANING OF TEACHING AND THE STRATEGIES FOR STRENGTHENING ITS PERFORMANCE}

\author{
Francisca Bertilia Chaves Costa ${ }^{1}$ \\ Luiza Valeska de Mesquita Martins ${ }^{2}$ \\ July Grassiely de Oliveira Branco ${ }^{3}$ \\ Patrícia Passos Sampaio 4 \\ Ana Maria Fontenelle Catrib ${ }^{5}$
}

\begin{abstract}
Resumo: Objetivou-se identificar o significado de ser docente na educação a distância na perspectiva de professores, bem como identificar as estratégias de fortalecimento para a sua atuação. Realizou-se uma pesquisa descritiva com abordagem qualitativa a partir de 11 entrevistas com docentes, com um ano de experiência nessa modalidade de ensino, de uma instituição de ensino superior da cidade de Fortaleza/Ceará em 2017. As entrevistas foram gravadas e transcritas, logo após foram ponderadas por meio da análise de conteúdo, mediante Parecer de aprovação do Comitê de Ética n ${ }^{\circ}$ 1.795.390. Os resultados foram analisados a partir de duas categorias temáticas: 1) O significado de ser docente na EaD; e 2) Estratégias de fortalecimento do ensino na educação a distância. Diante da diversidade de possibilidades oriundas das tecnologias em que a sociedade contemporânea se encontra imersa, ressalta-se a necessidade de os educadores ressignificarem sua prática docente para a inserção dessas em seu contexto educacional.
\end{abstract}

Palavras-chave: Educação a Distância; Docentes; Tecnologia.

\begin{abstract}
The objective was to identify the meaning of being a teacher in distance education from the perspective of teachers, as well as to identify the strategies for strengthening their performance. This is a descriptive research, with a qualitative approach was conducted from 11 interviews with teachers, with one year of experience in this type of teaching, from a Higher Education Institution of the city of Fortaleza / Ceará in 2017. The interviews were recorded and transcribed. afterwards, they were weighted through content analysis, upon approval of Ethics Committee no. 1,795.390. The results were analyzed from two thematic categories: 1) The meaning of being a teacher in $\mathrm{EaD}$; and 2) Strategies for strengthening teaching in distance education. We can claim that, given the diversity of possibilities resulting from the technologies in which contemporary society is submerged, we should highlight the need for educators to reframe their teaching practice for introducing these technologies in their educational context.
\end{abstract}

Keywords: Education Distance; Faculty; Technology.

\footnotetext{
${ }^{1}$ Doutoranda do Programa de Pós-Graduação em Saúde Coletiva pela Universidade de Fortaleza. Mestre em Enfermagem pela Universidade Federal do Ceará. Docente do Centro Universitário Fametro, Fortaleza, Ceará, Brasil. E-mail: bertilia_chaves@ hotmail.com

${ }^{2}$ Mestranda do Programa de Pós-Graduação em Saúde Coletiva pela Universidade de Fortaleza. Bolsista FUNCAP, Fortaleza, Ceará, Brasil. E-mail: valeskamesquita@ hotmail.com

${ }^{3}$ Doutoranda do Programa de Pós-Graduação em Saúde Coletiva pela Universidade de Fortaleza. Bolsista FUNCAP. Mestre em Saúde Coletiva pela Universidade de Fortaleza, Fortaleza, Ceará, Brasil. E-mail: julybranco.upa@gmail.com

${ }^{4}$ Doutora em Saúde Coletiva pela Universidade de Fortaleza. Docente da Universidade de Fortaleza, Fortaleza, Ceará, Brasil. E-mail: patriciap@unifor.br

${ }^{5}$ Docente do Programa de Pós-Graduação em Saúde Coletiva da Universidade de Fortaleza. Pesquisadora CNPq, Fortaleza/Ceará, Brasil. E-mail: catrib@unifor.br
} 


\section{Introdução}

Diante das mudanças ocorridas com a expansão do capitalismo e dos avanços tecnológicos da contemporaneidade, a educação apresenta como reflexo a redefinição nas formas de ensino oferecidas. Atualmente, há necessidade de se considerar dentro do contexto educacional duas modalidades de ensino: presencial e a distância. A primeira, utilizada em cursos regulares de ensino, apresenta em um mesmo espaço físico e de tempo o professor e o aluno em interação. Já a segunda traz a proposta de que esses atores se encontrem separados fisicamente no espaço e/ou no tempo, pois essa modalidade educacional ocorre a partir da utilização de recursos provenientes da tecnologia de informação e comunicação (TIC), podendo, no entanto, ocorrer ou não momentos presenciais (MORAN, 2009).

Frente a essa realidade, no Brasil, o que se encontra é um sistema educacional perpassado por inúmeras e inovadoras transformações em suas ferramentas de ensino e de aprendizagem, tendo como finalidade melhorar cada vez mais o processo de trabalho dos educadores, bem como a interação entre professores e alunos. Dentre essas transformações, destaque merece ser dado ao constante crescimento da educação a distância (EaD).

A definição de educação a distância no Brasil foi apresentada oficialmente no Decreto $\mathrm{n}^{\mathrm{o}} 5.622$, de 19 de dezembro de 2005, em seu artigo $1^{\circ}$ que conceituou a EaD como uma modalidade educacional na qual a mediação didático-pedagógica nos processos de ensino e aprendizagem acontece mediante a utilização de meios de tecnologias de informação e comunicação, com discentes e docentes desenvolvendo atividades educativas em diversos lugares ou tempos (BRASIL, 2005).

De acordo com o Ministério da Educação, no ano de 2010, 14,6\% das matrículas na graduação foram em cursos a distância, e 80,5\% correspondem ao total de 748.577 em instituições privadas. Segundo os dados, em dez anos, o número de matrículas em EaD cresceu de 5.359 (2001) para 930.179 (2010), um crescimento considerável e relevante.

De acordo com o Ministério da Educação (BRASIL, 2016), transformações importantes efetuaram-se nas políticas para a educação superior no Brasil, sobretudo, após a aprovação da Constituição Federal (CF) de 1988 e, especialmente, após a aprovação da Lei de Diretrizes e Bases da Educação Nacional (LDB) em 1996. Tais dispositivos confirmam a educação como direito e, na LDB, estão explícitas as bases para a educação superior e, no seu destaque, a EaD (BRASIL, 2016). 
Em consonância com esse desenvolvimento educacional observa-se também que a sociedade esteve e ainda permanece em constante mudança de paradigmas, pois, atualmente, encontra-se imersa em um mundo movido por ferramentas tecnológicas e, assim, a cada dia, novos fenômenos se apresentam. Dentro desse contexto, o docente que vivenciou por muitos anos o modelo de ensino presencial percebe a necessidade de qualificar-se cada vez mais em busca de novas ferramentas de ensino que envolvam os alunos, tornando-os mais motivados, interativos e colaboradores do processo de ensino e aprendizagem.

Cada vez mais novos paradigmas estão invadindo a sociedade do conhecimento, e o terceiro milênio exigirá mudanças na educação formal, que não está dando conta do ensinar e aprender, pois muitos docentes não conseguem ensinar seus alunos e também alunos não conseguem aprender (BRASIL; OSTERNE, 2018).

Dentro dessa abordagem, detecta-se que ao longo da história da humanidade muitas mudanças foram proporcionadas pelo avanço tecnológico, em especial o desenvolvimento das TICs, o que ocasionou a reconfiguração do processo de ensino e aprendizagem da educação a distância, além da revisão dos papéis dos atores envolvidos nesse contexto (SOUZA; FRANCO; COSTA, 2016).

$\mathrm{Na} \mathrm{EaD}$, diferente da atividade realizada de forma presencial, o professor tornase um mediador do aprendizado, no lugar do detentor/transmissor de saberes, tendo que aprender a trabalhar com tecnologias de informação e comunicação, além de trabalhar de forma coletiva e cooperativa, portanto, exige-se dele uma prática pedagógica muito diferente da prática desenvolvida no ensino presencial. Então, observa-se a importância de conhecer como os professores compreendem o significado de ser um educador dentro da modalidade de ensino a distância, e ainda quais as estratégias utilizadas para o fortalecimento de sua atuação.

A EaD apresenta como principal propósito a "quebra" da relação "face to face" entre docentes e discentes, provando que o processo de ensino e aprendizagem pode existir sem a obrigatoriedade de um agrupamento de alunos dentro de uma sala de aula, em um mesmo tempo e espaço físico. A modalidade de ensino a distância permite que o aluno trilhe seu próprio caminhar, decida sobre seu processo formativo de forma individual e com autonomia (MORAES NETO; TOMELIN, 2014).

Autores identificam que o uso de um ambiente virtual de aprendizagem e tecnologia proporciona melhor aprendizagem, no entanto, somente esses elementos não fazem uma completa diferença, deve existir sempre uma organização de qualidade nessa 
modalidade de ensino e, sobretudo, a mediação satisfatória por parte do corpo docente pode e deve proporcionar uma aprendizagem significativa (VARGAS-CUBERO; VILLALOBOS-TORRES, 2018).

Definiram-se as seguintes questões de pesquisa: Qual o entendimento dos professores sobre exercer a docência na educação a distância? Quais as estratégias utilizadas nessa modalidade de ensino? Assim, o presente trabalho objetivou identificar o significado de ser docente na educação a distância a partir da perspectiva de professores, bem como as estratégias de fortalecimento de sua atuação.

\section{Percurso metodológico}

Trata-se de um estudo descritivo de abordagem qualitativa em referência ao trabalho apresentado no $7^{\circ}$ Congresso Ibero-Americano em Investigação Qualitativa (COSTA et al., 2018).

Participaram desta pesquisa profissionais docentes envolvidos e atuantes na modalidade de ensino a distância, com pelo menos um ano de experiência em uma instituição de ensino superior (IES) da cidade de Fortaleza/Ceará, que conta com um quadro de 25 professores relacionados com a EaD.

Desse total, 11 professores aceitaram participar de forma voluntária do estudo mediante convite, via e-mail. Após a confirmação de aceite, houve um agendamento prévio com cada participante, para a realização da entrevista em seu próprio local de trabalho, de acordo com sua disponibilidade de horários. No dia e horário agendados por cada participante para a realização da entrevista ocorreu a assinatura do Termo de Consentimento Livre e Esclarecido (TCLE) para firmar a aceitação em participar do estudo.

Foi utilizada como procedimento para a coleta de dados a técnica de entrevista semiestruturada, que se baseou em um roteiro previamente estabelecido contendo perguntas abertas, tais como: “Qual o sentido em ser docente na EaD?”, permitindo ao entrevistador fazer questionamentos não previstos no referido roteiro com a finalidade de aprofundar o tema em questão (SAMPIERE; COLLADO; LUCIO, 2013). A partir da realização da entrevista outras perguntas surgiram, como: "Quais as suas estratégias para o fortalecimento da modalidade de ensino a distância?”.

As entrevistas foram realizadas de forma individual, com garantia de sigilo e anonimato diante das informações prestadas, durante os meses de março e abril de 2017. 
Para responder ao objetivo utilizou-se a entrevista semiestruturada como técnica de coleta de dados, por possuir um caráter investigatório, fazendo com que os participantes da pesquisa pensassem acerca do tema em questão. Esse tipo de entrevista possibilita a manifestação de aspectos subjetivos que evidenciam motivações que não são claras, ou mesmo conscientes, de maneira espontânea. Sua utilização acontece quando se buscam percepções e entendimento sobre a natureza geral de determinada questão, abrindo espaço para uma interpretação, pois o participante aborda de forma livre o tema proposto (MINAYO, 2015).

Para totalizar este número de entrevistados utilizou-se o critério de saturação que, segundo Fontanella, Ricas e Turato (2008, p. 17)

\begin{abstract}
É uma ferramenta conceitual frequentemente empregada nos relatórios de investigações qualitativas em diferentes áreas no campo da Saúde, entre outras. É usada para estabelecer ou fechar o tamanho final de uma amostra em estudo, interrompendo a captação de novos componentes. [...] O fechamento amostral por saturação teórica é operacionalmente definido como a suspensão de inclusão de novos participantes quando os dados obtidos passam a apresentar, na avaliação do pesquisador, uma certa redundância ou repetição, não sendo considerado relevante persistir na coleta de dados.
\end{abstract}

Todas as entrevistas foram gravadas com autorização prévia do participante, que a declarou a partir de sua autorização ao assinar o Termo de Consentimento Livre e Esclarecido.

Após esse momento as entrevistas foram transcritas na íntegra, para facilitar o trabalho de análise dos achados e, assim, promover discussões e interpretações acerca do tema.

A análise dos dados foi feita de acordo com a análise temática proposta por Minayo (2015). Após a transcrição das entrevistas, foram identificados os núcleos de sentido e ainda categorias temáticas referentes ao significado de ser docente na educação a distância. Sendo identificadas duas categorias temáticas: 1) O significado do ser docente na $\mathrm{EaD} ; 2$ ) Estratégias de fortalecimento do ensino na EaD. Para assegurar o anonimato dos participantes do estudo atribuiu-se a cada um desses a letra $\mathrm{P}$, correspondente a “professor” (P1 a P11), para representá-los nos resultados.

O presente estudo se fundamentou nos referenciais da bioética, autonomia, não maleficência, beneficência, justiça e equidade, respeitando os aspectos estabelecidos na Resolução 466/12 (BRASIL, 2013), com a finalidade de assegurar direitos e deveres dos participantes desta pesquisa, de acordo com o Parecer de aprovação do Comitê de Ética $\mathrm{n}^{\mathrm{o}} 1.795 .390$. 


\section{Resultados}

A partir da interpretação e análise das falas provenientes das entrevistas, identificaram-se como categorias temáticas, com base nos núcleos de sentido analisados e interpretados: O significado de ser docente na $\mathrm{EaD}$; e Estratégias de fortalecimento do ensino na $\mathrm{EaD}$.

\subsection{Caracterização dos participantes}

Os professores entrevistados apresentaram-se na faixa etária entre 29 e 55 anos de idade. Quanto ao sexo, sete eram do sexo feminino e quatro, do sexo masculino. Com relação ao tempo de experiência de docência na modalidade de ensino a distância, houve uma variação de 3 a 14 anos.

\subsection{O significado de ser docente na EaD}

A partir das indagações acerca das concepções de ser docente no contexto da educação a distância, os participantes atribuíram sentimentos como responsabilidade, desafio e sensibilidade diante dessa modalidade de ensino.

As falas abaixo demonstram que o exercício da docência no ambiente virtual requer do professor o desenvolvimento de competências para um melhor posicionamento como facilitador no processo de ensino e aprendizagem.

[...] tem uma responsabilidade que eu posso dizer assim até um pouco maior, né? O aluno, como ele fica um pouco livre pra fazer o horário dele, aí, o docente, ele tem que ter uma... digamos, uma maior sensibilidade, né? Talvez seja essa a palavra, ele tem que ser um pouco mais sensível pra compreender aquele aluno (P5).

[...] ser professor é... é... é ser desafiado todos os dias, é construir, é contribuir pro futuro, é ser responsável por um pouquinho da formação de cada um que passa pela gente $[\ldots](\mathrm{P} 6)$.

Eu acho o papel do docente fundamental em qualquer modalidade de ensino, acho que tanto no presencial, que é onde a gente tem a falsa ideia de que o papel docente é mais importante em virtude de está restrito ao ambiente da sala de aula, de ter o professor ministrando pessoalmente aquele conteúdo, mas pro EAD eu acho que a docência também é fundamental, embora a gente tenha um ambiente onde é disponibilizado aulas e materiais, inclusive videoaulas pro aluno. Então, eu acho que o papel do docente é fundamental, né, alguém que vai orientar e vai motivar esse aluno ao longo da caminhada dele, do trajeto (P9).

Ai... é encantador, é encantador, porque você passar informações e também receber informações, né, eu acho que é primordial. A gente não pode mais ter 
aquela visão de que a educação só parte do professor, é uma troca, e principalmente professor que trabalha com Educação a Distância, isso é constante $[\ldots](\mathrm{P} 7)$.

Eu acho que é um... (pausa) como educador é o mesmo papel, mas na EaD a gente precisa ter uma sensibilidade maior, porque o meu alcance, por não ter um contato direto, tem que ser mais sensível (P8).

Quando indagados sobre o uso de dispositivos tecnológicos que são utilizados no ensino a distância, os docentes, em sua maioria, partilhavam da ideia de que se faz necessário o desenvolvimento de estratégias que motivem os alunos a participar mais e que isso acaba exigindo do docente maior sensibilidade, investimento e capacitação, como demonstram as falas a seguir:

[...] na educação a distância você tem que ser um pouquinho mais sensível. Tá procurando sempre algumas ferramentas que busquem esse aluno, que façam que ele fique mais empolgado a mexer no conteúdo, né, então você tem que desbravar (P4).

[...] a docência me força a procurar estar atualizado, a procurar estar sempre dentro do que o mercado está pedindo. E a docência, ela tem uma importância muito grande na minha vida, né... Eu me realizo podendo contribuir com o que eu conheço, com meus conhecimentos (P3).

[...] o professor, ele, como docente, na sua atividade, ele promove uma série de situações que envolvem a questão da aprendizagem, mas uma aprendizagem significativa não é só que o aluno aprenda aquilo que é do conteúdo, mas que ele aprenda a fazer algo com aquilo, desenvolva, para além desse fazer, uma dimensão de cidadania. E na EaD mais ainda, porque você tem que lidar com alguém que está remoto, então você tem que imaginar essa pessoa, é imaginar quem está na outra ponta (P11).

\subsection{Estratégias de fortalecimento do ensino na EaD}

As estratégias utilizadas no ensino a distância são de suma importância não só para facilitar a assimilação dos conteúdos ministrados, como também para minimizar os efeitos da distância no ambiente virtual. Elas visam à aproximação entre docente e discente, buscando conhecer as especificidades e subjetividades de cada aluno.

Nesse contexto, os docentes lançam mão da criatividade desenvolvendo ações para fortalecimento dos vínculos entre aluno e professor, mostrando-se presentes, mesmo que virtualmente. As falas descritas a seguir evidenciam tais achados.

[...] a gente procura sempre estar, mesmo virtual, mas estar sempre presente, né, não deixar que ele fique com uma dúvida por muito tempo, quando ele manda um torpedo, ou manda um email, ou entra no fórum. É sempre tentar ao máximo, o mais rápido possível, responder, pra que ele não sinta essa distância, esse distanciamento entre a disciplina $\mathrm{EaD}(\mathrm{P} 3)$.

A gente usa a plataforma online, né, utiliza grupo do Facebook, e o Messenger... a gente agora tá gravando uns vídeos que fazem surtir mais efeito no Facebook... E eu gosto muito do fórum (P7). 
[...] um professor deve estar sempre conduzindo, orientando, ensinando o caminho, como é que acessa, esclarecendo dúvidas, e inclusive motivando o aluno a continuar vinculado à disciplina e a tá sempre atualizado no conteúdo, trazendo novas ideias, novas ferramentas (P9).

[...] você vai tornar, por exemplo, a comunicação não só efetiva, mas afetiva, mais afetuosa, mais acolhedora. Então, na função de docente, você tá lidando com pessoas que tão lendo aquilo que você tá escrevendo e tão interpretando de diversas maneiras. Então você tem que ser cada vez mais preciso naquilo que você quer dizer, mais objetivo, mas, ao mesmo tempo, mais afetuoso, acolhedor, porque alguém que já está distante pode se tornar mais distante ainda se não perceber que está sendo chamado, né, que está sendo, vamos dizer assim, atraído para um campo de discussão. Então envolve um relacionamento profundo, pedagogicamente falando, linguagens, códigos, que permitam fazem com que as pessoas possam acessar aquilo, entender, criar uma cumplicidade digital, fundamental nesse processo todo, e fazer com que as pessoas sintam que você tá lá presente, ao lado (P11).

\section{Discussão}

Diante dos resultados provenientes das entrevistas realizadas com os docentes, identificou-se que, diante da caracterização dos participantes desta pesquisa, quando comparados com dados provenientes da literatura científica, a predominância de docentes ou docentes/tutores do sexo feminino assemelha-se a inúmeros estudos realizados no Brasil (DE SOUTO; TENÓRIO; TENÓRIO, 2014; CALDAS et al., 2013).

Dentre as motivações que fazem com que os docentes optem por esta forma de ensino, Barbosa e Ursi (2019 p.168) afirmam que "ampliar conhecimentos e se atualizarem são as grandes motivações declaradas pelos educadores participantes, seguidas pelo anseio de aprimorar as metodologias de ensino".

A partir da primeira categoria temática proposta para este estudo, $O$ significado de ser docente na EaD, compreende-se, segundo Chaquime e Mill (2016), que, no decorrer da prática docente, existe uma busca contínua do professor pela ampliação de seus saberes, desde sua formação inicial, levando em consideração o contexto laboral no qual está inserido, bem como a articulação com as interações que estabelece com os alunos. Com isso, ele reinterpreta e ressignifica sua prática em prol do desenvolvimento e melhoria em sua atuação.

Nunes et al., (2019, p. 1) ressaltaram que o professor da modalidade de ensino a distância, dentre sua diversidade de atributos, deve "ser capaz de compartilhar conhecimentos, gerir grupos, ser dialógico, além de apresentar empatia, postura ética, competência interpessoal e disposição a novas aprendizagens”. 
Achados semelhantes aparecem em um estudo nacional que investigou as percepções dos docentes tutores no ensino a distância sobre as competências necessárias para o desenvolvimento de tais atividades. Os participantes desse estudo afirmaram que se consideravam facilitadores no processo de ensino e aprendizagem, o que requer um aperfeiçoamento contínuo e o desenvolvimento de estratégias de motivação por parte desses, para que os alunos sigam motivados e participativos (SILVA et al., 2016).

Por meio da análise das entrevistas desta pesquisa, observou-se que a sensibilidade retratada na fala dos participantes vem suprir uma lacuna referida por pesquisas que mencionam falhas no processo de comunicação entre docente e discente, o que fragiliza o processo de ensino e aprendizagem do sistema educacional (PAIVA et al., 2014).

Dentro desse contexto, Moore e Kearsley (2011) discutem em seu estudo que na $\mathrm{EaD}$, por apresentar a mediação por meio de diversos recursos tecnológicos, faz-se essencial na prática docente combinar diferentes mídias para auxiliar o aprender discente, pois, "Quanto mais alternativas de mídia são oferecidas, mais eficaz o curso de educação a distância tem possibilidade de ser para uma faixa mais ampla de alunos" (MOORE; KEARSLEY, 2011, p. 101).

Assim, é importante ressaltar que "o trabalho com educação a distância exige domínio das competências e, principalmente, o conhecimento de como articular os saberes dos sujeitos no coletivo" (GILBERTO, 2013, p. 284).

Sabe-se que o trabalho realizado na educação a distância compreende a necessidade de ser regido por condições especiais, pois se trata-se de um trabalho docente que apresenta uma certa complexidade, em especial, do ponto de vista trabalhista, pois existem diferentes atores atuantes nessa modalidade de ensino, como os docentes-autores (conteudistas), bem como os docentes-formadores (coordenador da disciplina e tutores) (MILL et al., 2011).

Para Belloni (2008) a EaD está cada dia mais presente, no contexto da sociedade, como uma modalidade de ensino adequada e desejável para atender às novas demandas educacionais decorrentes das transformações oriundas da nova ordem econômica mundial.

Assim, a expansão da EaD possibilitou e ainda continua possibilitando o acesso ao sistema educacional aos mais diversos tipos de público, além disso, das mais variadas localidades. O que promoveu e promove a inclusão de atores sociais que muitas vezes não teriam a possibilidade de frequentar cursos presenciais, seja pela ausência de oferta 
dos mesmos nos municípios em que residem, seja pela dificuldade de locomoção ou até mesmo por falta de tempo (LUPEPSO; SÁ, 2018).

No que se refere à necessidade de atualização constante, De Souto, Tenório e Tenório (2014, p. 44) referem que, "para acompanhar o ritmo dessas mudanças, os profissionais da área educacional, além da renovação de seus conhecimentos por meio de formação continuada, precisam acompanhar as inovações técnicas e tecnológicas surgidas a cada novo ano", evidenciando, desta forma, uma busca contínua pelo saber e pelo aprender.

$\mathrm{Na}$ segunda categoria, Estratégias de fortalecimento do ensino na EaD, considerando que o aluno, nessa modalidade de ensino, estuda sozinho grande parte do tempo, identificou-se que a utilização de ferramentas que proporcionem mais interação entre os alunos e entre alunos e professores pode auxiliar e estimular para que venham a se tornar aprendizes ativos. Assim, nesta categoria há diversificadas ações que compõem o quadro de fortalecimento dessa modalidade de ensino: estratégias criativas para estimular a criticidade, empoderamento e autonomia intelectual do aluno.

A necessidade da presença e estímulo do aluno no ambiente virtual relatada pelos docentes corrobora com estudos que reforçam a necessidade da constante transformação e estimulação dos alunos, evitando, assim, a evasão dos mesmos (REIS; SALLES, 2017; LOURENÇO, 2011).

Evidências de estudos nacionais reforçam a necessidade de motivação e empoderamento do discente na era digital: "mais do que nunca os alunos precisam estar motivados para a construção da autonomia intelectual sob pena de ser excluídos desse processo formativo construtivista” (DE LIMA; DE LIMA, 2018 p.65).

Neste contexto, o ensino é uma ferramenta utilizada para que o sujeito seja um profissional crítico, para pensar, aprender e se conhecer como cidadão do mundo. Por isso, a educação por meio da 'decoreba', de questões sem nexo, deve ser banida e exorcizada das escolas, sejam presenciais ou à distância. As instituições de ensino devem reelaborar o conhecimento produzido pela humanidade acoplado ao conhecimento de mundo, para que o educando possa apropriar-se desse conhecimento e agir sobre o mundo com competência (BRASIL; OSTERNE, 2018).

As atividades adotadas pelos participantes da pesquisa vão ao encontro das preconizações do Ministério da Educação (2016), as Diretrizes e Normas Nacionais para a oferta de Programas e Cursos de Educação Superior na Modalidade a Distância, homologadas em dezembro de 2015 pelo Conselho Nacional de Educação, que fazem 
menção às relações humanas como espaço de discussão onde se tenha qualidade nessas relações. E ainda que haja condições reais de infraestrutura, laboratórios adequados para as ofertas dos cursos, pessoal de apoio qualificado, políticas de acesso, acompanhamento e avaliação compatíveis com as necessidades dos alunos (BRASIL, 2016).

No entanto, o docente da EaD precisa ter um olhar reflexivo sobre suas ações, para que, a partir de suas estratégias de atuação, estabeleça uma relação harmoniosa com seu aluno. Precisa fazer com que o discente, distante fisicamente, sinta-se próximo e envolvido no contexto (WUNSCH; SOARES; GRINBERGA, 2018). Castagnaro (2019 p.334) acredita que, "se o professor estiver atento às interações e aos alunos, o rendimento dos alunos será maior e o nível de desistência e reprovação menor".

Dentro dessa contextualização, a educação a distância ainda proporciona aos discentes um espaço para refletirem sobre o conhecimento, o que na modalidade presencial pode não acontecer, podendo ainda contribuir para que possa elaborar seu projeto de vida e participar ativamente na produção de uma sociedade mais justa, democrática e, acima de tudo, mais humana, além disso, ele teria um tempo maior para seus questionamentos (BRASIL; OSTERNE, 2018).

Os autores supracitados ressaltam que a Educação a Distância não deve ser reduzida a questões metodológicas ou apenas ao uso das novas tecnologias, deve ser vinculada à luta por uma vida pública em que o diálogo, a tolerância e o respeito à diferença estejam ligados aos direitos de uma prática social justa e democrática. Dessa forma, as instituições de $\mathrm{EaD}$ devem ser espaços de educação, ao invés de um ambiente de distribuição de 'saber-produto a clientes consumidores', e não esquecer que, quando se fala em educação, é necessário ter a intenção de educar seres humanos que pensam e fazem (BRASIL; OSTERNE, 2018).

Fato que merece destaque ainda corresponde ao disposto na Resolução $\mathrm{n}^{\circ}$. 1/2016, em seu artigo $9^{\circ}$, que indica que a educação a distância é uma modalidade "indissociável do desenvolvimento institucional" e, assim, seus pressupostos precisam estar integrados ao projeto de uma instituição (BRASIL, 2016).

\section{Considerações finais}

Frente aos achados desta pesquisa, observa-se que na contemporaneidade há uma diversidade de possibilidades oriundas das novas tecnologias. Diante desse fato, os educadores devem ressignificar sua prática docente, não perdendo a oportunidade de 
inserir as tecnologias de informação e comunicação em suas práticas de ensino, pois a educação jamais pode ficar fora deste contexto revolucionário.

Essas inovações tecnológicas aliadas com as habilidades do docente/tutor em desenvolver estratégias motivadoras são capazes de estimular os estudantes dentro do seu processo de aprendizagem, possibilitando que eles se tornem sujeitos ativos e responsáveis pelo seu processo de aprendizagem e crescimento.

E, diante deste quadro em evolução, a educação a distância torna-se um elementochave do sistema educacional, por apresentar a capacidade de levar o conhecimento a lugares remotos, permitindo o acesso a todos em qualquer lugar e horário.

Assim, apesar dos questionamentos e críticas acerca dessa modalidade de ensino, não se deve desqualificar essa nova forma de aprender baseado em discursos vazios e sem argumentos plausíveis. No entanto, recomenda-se cautela na utilização do ensino a distância, devendo-se estudar suas possibilidades de uso como ferramenta que pode agregar e não substituir o ensino regular, possibilitando assim uma nova forma de aprender.

Como limitações para este estudo, identificou-se que os docentes, em uma grande proporção, relataram apenas questões da modalidade de ensino a distância referentes à sua instituição de ensino, devido à permanência nesta desde do início de seu trabalho na $\mathrm{EaD}$, e, assim, não eram conhecedores de outras experiências.

Dessa forma, trabalhos futuros que envolvam a abordagem qualitativa e a $\mathrm{EaD}$ devem ser realizados para que se possa melhor escutar a voz do professor, saber seus anseios e suas dificuldades diante dessa prática de ensino.

\section{Referências}

BARBOSA, P. P.; URSI, S. Motivação para formação continuada em Educação a Distância: um estudo exploratório com professores de Biologia. Revista Electrónica de Enseñanza de las Ciencias, Vigo, v. 18, n. 1, p. 148-172. 2019.

BELLONI, M. L. Educação à distância. 5. ed. Campos, São Paulo: Autores associados. 2009.

BRASIL. Congresso Nacional. Lei n. 9.394, de 20 de dezembro de 1996. Estabelece as diretrizes e bases da educação nacional. Brasília: 1996. Disponível em:

http://www.planalto.gov.br/ccivil_03/leis/19394.htm. Acesso em: 15 abr. 2018.

BRASIL. Congresso Nacional. Decreto n. 5.622, de 19 de dezembro de 2005. Regulamenta o art. 80 da Lei 9.394, de 20 de dezembro de 1996, que estabelece as diretrizes e bases da educação nacional. Brasília: 2005. Disponível em: http://www.planalto.gov.br/ccivil_03/_ato2004-2006/2005/decreto/d5622.htm. Acesso em: 15 abr. 2018. 
BRASIL. Conselho Nacional de Educação. Resolução n. 1, de 11 de março de 2016. Estabelece Diretrizes e Normas Nacionais para a Oferta de Programas e Cursos de Educação Superior na Modalidade a Distância. Brasileira: 2016. Disponível em: http://portal.mec.gov.br/index. php?option=com_docman\&view=download\&alias=31361parecer-cne-ces-564-15-pdf\&Itemid=30192. Acesso em: 17 mar. 2018.

BRASIL. Conselho Nacional de Saúde. Resolução n 466, 2012. Diretrizes e Normas regulamentadoras de pesquisa envolvendo seres humanos. Brasília, 2013.

BRASIL, W. L.; OSTERNE, M.S.F. Educação a distância e o educador do século XXI. Revista Expressão Católica, Quixadá, v. 7, n. 2, p. 43-51, jul./dez. 2018.

CALDAS, C. B. et al. Satisfação e engajamento no trabalho: docentes temáticos e auxiliares da EAD de universidade privada brasileira. Gerais: Revista Interinstitucional de Psicologia, Belo Horizonte, v. 6, n. 2, p. 225-237, jul. 2013. Disponível em: http://pepsic.bvsalud.org/scielo.php?script=sci_arttext\&pid=S198382202013000200006\&lng=pt\&nrm=iso. Acesso em: 23 mar. 2018.

CASTAGNARO, F. C. Qualidade do Feedback e Satisfação Internacional dos Participantes no Ambiente Virtual de Aprendizagem (AVA). In: SEMINÁRIO DOS ALUNOS DOS PROGRAMA DE PÓS-GRADUAÇÃO DO INSTITUTO DE LETRAS/UFF, 2018, Niterói. Anais... Niterói: Universidade Federal Fluminense, 2019. p. 318-336.

CENSO. EAD.BR. Associação Brasileira de Educação a Distância. São Paulo: Pearson Education do Brasil. 2010.

CHAQUIME, L. P.; MILL, D. Dilemas da docência na educação a distância: um estudo sobre o desenvolvimento profissional na perspectiva dos tutores da Rede e-Tec Brasil. Revista Brasileira de Estudos Pedagógicos, [S.I.], v. 97, n. 245, p.117-130, abr. 2016.

COSTA, F. B. C. C. et al. O significado de ser docente na educação a distância e as estratégias de fortalecimento para sua atuação. In: CONGRESSO IBERO-AMERICANO EM INVESTIGAÇÃO QUALITATIVA, 7., 2018, Fortaleza. Anais... Fortaleza: Ludomedia, 2018.

DE SOUTO, E. V., TENÓRIO, T., TENÓRIO, A. Percepções sobre a competência socioafetiva de cordialidade e a humanização da tutoria a distância. EaD em FOCO, Rio de Janeiro, v. 4, n. 1, jun. 2014.

FONTANELLA, B. J. B.; RICAS, J.; TURATO, E. R. Amostragem por saturação em pesquisas qualitativas em saúde: contribuições teóricas. Cadernos de Saúde Pública, Rio de Janeiro, v. 24, n. 1, p. 17-27, jan. 2008. Disponível em: http://www.scielo.br/pdf/csp/v24n1/02.pdf. Acesso em: 23 abr. 2018.

GILBERTO, I. J. L. A educação a distância no ensino superior e a lógica das competências. Revista Gestão Universitária na América Latina, Florianópolis, v. 6, n. 1, p. 273-286, jan. 2013.

LOURENÇO, R. V. O Papel do Professor Tutor na minimização da evasão na educação a distância. Anuário da Produção Acadêmica Docente, Valhinhos, v. 5, n. 10, p. 175-188, 2011.

LUPEPSO, M.; SÁ, R. A. Estado do conhecimento na educação a distância: repensando a formação docente inicial e continuada. Revista Intersaberes, Curitiba, v. 13, n. 28, p. 22-36, jan./abr. 2018. 
DE LIMA, M. A. R.; DE LIMA, M. D. N. R. A era digital e os desafios formativos no interior da Amazônia brasileira. Revista Labirinto, Porto Velho, v. 29, n. 1, p. 52-67, jul./dez. 2018.

MILL, D. et al. O desafio de uma interação de qualidade na EAD: o tutor e sua importância neste processo. Cadernos da Pedagogia, São Carlos, v. 2, n. 4, p. 112-118, ago./dez. 2011. Disponível em: http://www2.ufmg.br/ead/ead/Home/Biblioteca-Digital/Referencias/O-desafiode-uma-interacao-de-qualidade-na-educacao-a-distancia-OTutor-e-sua-importancia-nesseprocesso. Acesso em: 15 abr. 2018.

MINAYO, M. C. O desafio do conhecimento: pesquisa qualitativa em saúde. 13. ed., São Paulo: Hucitec. 2015.

MORAES NETO, R. A.; TOMELIN, J. F. O papel do tutor na interface pedagógica da EAD. São Paulo. 2014. Disponível em: http://www.abed.org.br/hotsite/20-ciaed/pt/anais/pdf/356.pdf. Acesso em: 15 fev. 2018.

MORAN, J. M. O que é educação à distância. Universidade de São Paulo. 2009. Disponível em: http://www2.eca.usp.br/moran/wp-content/uploads/2013/12/dist.pdf. Acesso em: 20 abr. 2018.

MOORE, M. G.; KEARSLEY, G. Educação a distância: uma visão integrada. Tradução de Roberto Galman. São Paulo: Cengage Learning, 2011.

NUNES, A. R. et al. Docência na educação a distância: abordagem sobre o perfil profissional. Revista Internacional de Educação Superior, Campinas, v. 5, e019009, p. 1-16. 2019.

PAIVA, K. C. M. et al. Competências docentes ideais e reais em educação a distância no curso de administração: um estudo em uma instituição brasileira. Tourism \& Management Studies, Faro, v. 10, n. esp., p.121-128, dez. 2014.

REIS, M. C.; SALLES, M. R. R. A Relação entre o Tutor e o Aluno: Acolhimento Dádiva no Ensino a Distância. RIGS revista interdisciplinar de gestão social, Salvador, v. 6, n. 2, p. 157-166, maio/ago. 2017.

SAMPIERI, R. H.; COLLADO, C. F.; LUCIO, M. P. B. Metodologia de pesquisa. 5. ed. Porto Alegre: Penso. 2013.

SILVA, L. S. et al. Formação Continuada em Educação a Distância: Percepções sobre as competências na atuação do professor tutor. Em Rede Revista de Educação a Distância. Porto Alegre, v. 3, n. 2, p. 252-265, 2016.

SOUZA, S.; FRANCO, V.S.; COSTA, M.L.F. Educação a distância na ótica discente. Educação e Pesquisa, São Paulo, v. 42, n. 1, p. 99-113, jan./mar. 2016.

VARGAS-CUBERO, A. L.; VILLALOBOS- TORRES, G. El uso de plataformas virtuales y su impacto en el proceso de aprendizaje en las asignaturas de las carreras de Criminología y Ciencias Policiales, de la Universidad Estatal a Distancia de Costa Rica. Revista Electrónica Educare, Cidade do Panamá, v. 22, n. 1, p. 20-39, ene./abr. 2018.

WUNSCH, L.P.; SOARES, A.P.; GRINBERGA, I.M. Ferramenta de iniciação à pesquisa: avaliação significativa na EaD. Revista Iberoamericana de Educación, Madrid, v.77, n.1, p. 35-54, jun. 2018.

Recebido em: 22 de fevereiro de 2019.

Aceito em: 25 de julho de 2019. 